\title{
Leader-member Exchange and Job Performance: Comparing the Influence of Actual and Perceived Cultural Similarity
}

\author{
Chang $\mathrm{Liu}^{1, *}$ \\ ${ }^{1}$ Alliance Manchester Business School, University of Manchester, Manchester M139PL, Britain \\ *Corresponding author. Email: changliu306@hotmail.com
}

\begin{abstract}
Building on similarity-attraction theory and social exchange theory, this study investigates the relationship between the actual and perceived cultural similarity, Leadership-Member Exchange (LMX) and job performance. Two fundamentally different approaches to conceptualizing cultural similarity are put forth in this study: real actual cultural similarity which relies on secondary sources data to calculate and infer the degree to which one is actually similar to another individual in cultural attribute, and perceived cultural similarity which subjectively evaluate psychic cultural similarity. Different from prior researches on similarity-LMX relationship that mostly involve demographic domain, the present study features the following: 1) focusing on comparing influence of actual cultural similarity and perceived cultural similarity on LMX, authenticating perceived cultural similarity is a stronger predictor of work outcomes; 2) verifying the role of LMX as a mediator between perceived cultural similarity and job performance. Support for hypotheses was found in the empirical studies, conducted with data from more than 400 participants working in multi-cultural corporations. This research is innovative in theory and methodology which enriches managerial literature and sheds light on further cultureLMX study. Especially, a new perception-based measure developed in this study by combining several measures in exist literature would lead to more accurate assessment.
\end{abstract}

Keywords: Leadership-Member Exchange (LMX), Actual cultural similarity, Perceived cultural similarity, Job performance.

\section{INTRODUCTION}

It's essential to understand how cross-culture relates to organizational behavior and how crossing national borders creates specific challenges and opportunities for leadership in global setting. Therefore, the present research and implications should advance knowledge beyond prior reviews, as our purpose is to analyze the extent to which the process of the impact of the actual cultural similarity and perceive cultural similarity on LMX. And also, LMX quality can bridge the relationship between perceived cultural similarity and work outcomes.

LMX theory deals with individual relationships existed between supervisors and their subordinates. Early researches focusing on LMX posit that because of time pressure, leaders establish special relationships with a small number of high-level of LMX members. These individuals become insiders, being trusted and looked after by their leaders, and more likely to be privileged. And most low-level LMX subordinates do not have anything beyond formal obligations. (Bauer \& Green, 1996 [1]; Liden \& Maslyn, 1998 [2]). A fundamental assumption of differentiation is at the very heart of LMX theory (Henderson et al., 2009) [3]. LMX differentiation involves with a process and consequence of dynamic interdependence of activities by which leaders develop different quality relationships (LMX) with each member of their work unit. (Martin, et al., 2017) [4].

Notwithstanding researches have revealed that LMX is relevant across a wide range of countries and cultures, Aycan and Kanugo (2001) [5] suggest that environmental contexts (including 
sociocultural context) influence behavioral and interpersonal characteristics (such as leadership and managerial practices), which in turn influences individual outcomes (such as performance, effectiveness, and organizational attitudes). One of the main reasons that researchers are interested in the measurement and conceptualization of organizational environments is to test contingency theory predictions about its relationship with organizational structures, processes, technologies, and outcomes (Boyd, 1993) [6]. Cultural variables have been found associated with the process of Leader-member exchange (eg. Dulebohn, et al., 2012 [7]; Rockstuhl, et al., 2012 [8]). However, organizational behaviors rely on managerial perceptions of the firm' s environment (Anderson and Paine, 1975 [9]). Therefore, using perceptual data in assessing cultural differences is suggested (Beugelsdijk, et al., 2018 [10]).

Hofstede (1980) [11] defined culture as "the collective programming of the mind which distinguishes the members of one human group from another". Culture is a complex, intangible and subtle phenomenon (Shenkar, 2001) [12].

Lott (2010) [13] described culture as:

There are many intersecting cultures that define each of us as individual persons. Some are large such as cultures of ethnicity, gender, social class, religion, sexual orientation, age, disability, and geographical location. Some are smaller occupation, political affiliation, special talent, educational institution, unions, or clubs. Cultures differ in size and also in how they are related to (or constructed from) hierarchies of power, domination, and access to resources.

Drawing on similarity-attraction theory, a research on the relationship between the actual cultural similarity and perceived cultural similarity and LMX and job performance is conducted in this study. Two fundamentally different approaches to conceptualizing cultural similarity are put forth in. One is actual cultural similarity (indirect measure), which relies on secondary sources data (indirect measure). Another is perceived cultural similarity (direct measure) which is subjective evaluation of psychic cultural similarity. Derived from the previous definition of actual similarity, the real actual of the cultural similarity is conceptualized as the degree to which one is actually similar to another individual in cultural attribute the perceived cultural similarity is defined as degree to which one believes oneself similar to another in cultural attribute. The evidence that individual's perception may differ from measures based on secondary sources can be used to help understand organizational behavior. According to social identity theory (Tajfel and Turner 1986) [14] and self-categorization theory (Turner et al. 1987) [15], actual cultural similarity in this study is assumed common perception of nation or cluster boundaries associated with a specific society or people and shared assumptions of cultural similarities. Perceived cultural similarities, by comparison, assumes each person has a unique subjective judgement about one's similarity in cultural attribute with that of the target. The similarity effect is "one of the most robust relationships in all of the behavioral sciences" and is "one of the best documented generalizations in social psychology" (Layton \& Insko, 1974) [16].

In this study, four dimensions of Power distance, Collectivism, Gender Egalitarianism, Assertiveness chosen from GLOBE's frame-work were examined as actual cultural similarity variables. These dimension conceptualizations were chosen because they were typical, having newly updated data. The author of this paper identified these cultural variables believing they are related to the ways in which individuals in organizations interact with one another and as such would have clear links to the relationship in the process of leader-members exchange. The perception based psychic cultural measure is also developed by combining several relevant measures in existed literature at present study since there is no proper measure before.

This research provides following contributions to the literature.

First, two main perspectives of cultural similarity (real actual vs. realms of psychology) on LMX and job performance are identified and examined for the first time. The two perspectives which based on different theoretical assumptions are critical to understanding the relation between cultural similarity and outcomes, while previous similarity studies related to LMX focus on demographic similarity variable (eg, Matkin, et al., 2012) [17]. There is strong theoretical support (e.g., similar attraction theory, Montoya, et al., 2008) [18] that perceived cultural similarity might be more attractive than actual cultural similarity and perceived cultural similarity would be a better predictor of individual outcomes than actual cultural similarity as the former reflect peoples' internal reality of their social environment. And the empirical research results are in line with the 
contention that perceptions are better predictors of a range of outcomes compared to actual measures (Cunningham, 2007[19]; Shemla, et al., 2016) [20].

Second, the LMX-based mechanism underlying the relationship between perceived cultural similarity and work performance is investigated for the first time in this study. In prior studies, LMX as a mediator can be found in many topics, for example, transformational leadership, negative affectivity, LMX quality and performance (Hui et al., 1999) [21]; jobs and organizations, LMX and performance (Gerstner \& Day, 1997) [22]; benevolent leadership, LMX and employees as a personal antecedent of work outcomes (Bass, 1993) [23]; CQ, LMX and voice behavior (Jiang, 2018) [24]. In the examinations of LMX's mediating role, Dulebohn et al, (2012) [25] tested mediation effects of 21 antecedents according to Cohen's criterion. They removed 12 of the antecedents from consideration (i.e., leaving 9 antecedents) in order to better establish the relationships between the important antecedents. They left the topics like similarity, perceived competence, affect or liking for future research.

The conceptual model is descripted as follows:

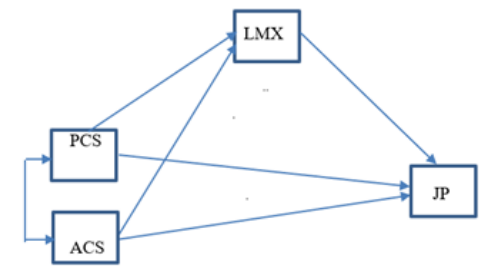

Figure 1 The model of comparing the effects of ACS with PCS on LMX and outcome.

ACS = actual cultural similarity PCS=perceived cultural similarity LMX=leader-member exchange.

\section{THEORETICAL BACKGROUND AND HYPOTHESES DEVELOPMENT}

\subsection{General Theories, Actual and Perceived Cultural Similarity, and LMX}

The two main theoretical premises that assume inverse relationships between diversity and team functioning or work outcomes are well supported propositions of social identity (Tajfel and Turner 1986) [14] and self-categorization theories (Turner, 1987) [15]. These theories posit that team members identify and classify themselves with others based on same features. Social identity and selfcategorization perspective are complemented by the similarity/attraction theories (Byrne, 1971) [26], which helps to interpret LMX agreement in this study that people likely category themselves and the others by cultural identity and conduct more positive interactions with those who are similar to them than with those who are dissimilar.

The author of this paper expatiates on an important distinction in cultural similarity that is reflected in the way it is conceptualized and measured. Derived from Byrne (1971) [26], actual cultural similarity refers to a situation in which two individuals share cultural attribute (indirect measure, i.e., using secondary data). Perceived cultural similarity (direct measure, i.e.,) refers a subjective image about one's similarity in cultural attribute with that of the target. The conceptual distinction between actual and perceived can be found in demographic similarity applied to organizational behavior researches (e.g., Cunningham et al., 2007[19]; Matkin, et al., 2012[17]), but not in cultural similarity and LMX study.

Nevertheless, some researchers argued that "Only perceived similarity is necessary to produce attraction" (e.g., Condon \& Crano, 1988 [27]; Ptacek \& Dodge,1995[28]). Perception of cultural diversity is a critical framework to resolve inconsistencies across studies. Harrison \& Gavin (2002) [29] asserted significantly that "if differences are to be meaningful, they must be perceived."

According to previous studies regarding convergent validity of objective and perceptual measures, moderate to strong correlations between the measurement of actual diversity and perceived diversity (Harrison\& Gavin, 2002 [29]) and weak 
to moderate correlations between archival figures and perceived estimates of diversity (e.g., Hooghe \& De Vroome, 2013 [30]) were reported. From the different "accuracy" estimates, we can infer that there are meaningful variations in people's estimates of diversity in their cultural diversity environment.

Unlike actual measures, the perception of cultural diversity is the a "mediating filter" (Downey and Slocum, 1975) [31] process in which sensory (i.e. stimuli) can be received from the diversity environment, then selecting and screening, organizing and interpreting them, finally resulting in action or thought patterns (Cook and Hunsaker, 2001) [32]. Their filter focused on the individual level of analysis and is cognitively based-including. The experiment of both laboratory and the field shows that perceived similarity, rather than actual similarity, being predictive of attraction in existing relationships.

People who are different in cognitive factors, such as attitudes, values, and beliefs towards the inclusion of cultural diversity, will react differently towards diversity stimuli because of personal characteristics. Experiences, memories, and interactions contribute to the information available. When both the supervisor and subordinate are similar to those perceptually identified, "automatic" categorization is likely to occur. The closer the subjective images developed by the leader and the subordinate, the more rapidly categorization occurs.

Therefore, it is our contention that when considering actual cultural similarity and perceived cultural similarity at the same time, perceived cultural similarity will have a greater impact than actual similarity on LMX quality. Based on above deduction, the proposal is put forward:

Hypothesis 1: Comparing with actual cultural similarity, perceived cultural diversity will be a strong predictor.

\subsection{Perceived Cultural Similarity Leader- Member Exchange and Job Performance}

Many researches show that LMX may operate as a mechanism through which antecedents affect consequences (Dulebohn, et al., 2012 [7]). Yet whether cultural similarity can be mediated by LMX variable have not been tested before.

Social identity theory remained an important concept, as leaders and employees may experience identity changes after working with each other. When the individuals' subjective view of cultural similarity to his supervisor (subordinate), positive evaluation and positive consequence in individual's task and social exchanges will occur.

According the conflict theory (Coleman, 2000) [33] and contact theory (Allport, 1954 [34]; Pettigrew \& Tropp, 2006) [35], during the interactions between supervisors and subordinates in the diversity setting, the mental process including cognitive factors leads those members who perceive cultural similarity with leaders to high LMX quality, resulting in better performance and those who perceive cultural dissimilarity to feel thread resulting in conflict with the leaders, causing low LMX quality, bringing about poor performance.

Diversity not only installs distinct processes related to positive and negative outcomes, but its effects also seem to depend on the characteristics of the perceiver. Global mindset has been described as a critical characteristic of effective global leadership development and success (Dekker, 2016 [36]). The individual, through understanding and respecting other culture, avoids the simplicity of assuming all culture are the same, and at same time, is not paralyzed by the complexity of the differences. So, a new perceived cultural similarity measure is developed by incorporating global mind set measure in perceived cultural similarity evaluation in this study reflecting the cognitive elements to cultural openness.

In light of Social Exchange Theory (Blau, 1964) [37], Resource Theory (Foa, 1980) [38] and Equity Theory (Erdogan \& Bauer, 2010) [39], the author of this paper proposes that perceived cultural similarity enables members to develop high LMX quality in a cross-cultural context. In turn, high quality of LMX, as an embodiment of easier access to information, support, resources, and opportunities, can facilitate them by going beyond formal obligations. While perceived cultural dissimilarity will probably cause low-LMX quality and those who have low-LMX are only assigned routine tasks, leading to perceptions of injustice in process and poor work performance.

The situations described above are in accord with relational leadership theory (RLT) which holds that relationships between supervisor and subordinates are vastly important in determining outcomes of employees (Brower, Schoorman, \& Tan, 2000) [40]. It is the quality of leader-member exchange that determines critical outcomes because 
the leaders and members both benefit from sharing positive perceptions of their relationship they devoted to (Maslyn \& Uhl-Bien, 2001) [41] and satisfied work outcomes (Cogliser, Schriesheim, Scandura, \& Gardner, 2009) [42].

Also, a meta-analysis conducted by Montoya,et al.,(2008)[18] shows that implications of perceived similarity, rather than actual similarity, being predictive of attraction in existing relationships.

According to the deduction above, $\mathrm{H} 2$ is proposed as following

Hypothesis 2: LMX quality can mediate the relationship between perceived cultural similarity and job performance

\section{METHODOLOGY}

\subsection{Participants}

Data for this study were collected in several multinational firms located in China. 553 participants including supervisors and subordinates respectively came from China, the United States, Italy, Germany, Japan, South Korea, etc. In total, 420 questionnaires were obtained, for a $76 \%$ response rate owing to well organized. Of these 420 individuals, a preliminary analysis revealed that $75.3 \%$ were male. The average age of the respondents was 31.65 , with the ages ranging from 22 to 58

\subsection{Measures}

All of the constructs in our study were operationalized using measures that had been used extensively in the management and organization literature, with well-established psychometric properties, including reliability estimates, construct and criterion-related validities. (Note: measure of perceived cultural diversity was combination of the items extracted from several measures). Both supervisors and subordinates responded to items of the questionnaire with English and Chinese versions.

\subsubsection{Actual Cultural Diversity}

The effects of actual cultural similarity were examined using Euclidean distance index based on Globe's (Javidan, et al., 2006) [43] dimensions of national culture between the supervisor and the members. In line with the concept of Euclidean distance, it computed their distance in a fourdimensional space as the square root of the sum of the squared differences in the scores on each cultural dimension. Formally,

$$
C D_{j}=\sqrt{\sum_{i=1}^{4}\left\{\left(I_{i j}-I_{i N}\right)^{2} / V_{i}\right\}} .
$$

where $\mathrm{CD} \mathrm{j}$ is the cultural distance between the country of member $j$ and the country of the supervisor, $\mathrm{I}_{\mathrm{ij}}$ is country of member $\mathrm{j}$ 's score on the ith cultural dimension, $\mathrm{I}_{\mathrm{iN}}$ is the score of the country of the supervisor on this dimension, and $V_{i}$ is the variance of the score of the dimension.

\subsubsection{Perceived Cultural Diversity}

The measure includes two parts: perspective with the subordinate and perspective with the supervisor (Mitchell et al., 2009) [44].

Perspective with the subordinate: To measure the degree to which the supervisor perceived himself or herself to share a similar perspective with the subordinate, 6 items were used. Two items (i.e., "My subordinate and I see things in much the same way" and "My subordinate and I are similar in terms of our outlook, perspective, and values") were from Turban and Jones (1988) [45], two items ("My subordinate and I think alike in terms of coming up with a similar solution for a problem" and "My subordinate and I handle problems in a similar way") were from Liden et al. (1993) [46]. The measure on a 5-point (1=strongly disagree and $5=$ strongly agree) Likert scale was rounded out.

Perspective with the supervisor: To measure the degree to which the subordinate perceived himself or herself to share a perspective with the supervisor, the 6 items used to measure a common perspective with the subordinate were modified. Specifically, the word supervisor was substituted for subordinate in each item (e.g., "My supervisor and I see things in much the same way"). Responses were made on a 5-point Likert scale (1=strongly disagree and $5=$ strongly agree).

Individual Global Mindset was included in this perceived cultural similarity measure. It was assessed through Global Attitude Protocol. The survey was created by Professor Pankaj Chemawat [47] (2011), who is a Global professor of Management and Strategy at the NYU Stem School of Business. The questionnaire included items such as: I speak multiple languages; I have lived in countries other than my home country; I enjoy traveling to and getting to know people from different parts of the world; Some of my closest 
friends are of nationalities different from mine. Items are measured on a 5-point Likert scale and all scores of questions from the questionnaire should be summed.

\subsubsection{LMX Quality}

Graen and Uhl-Bien's (1995) [48] 5-point scale ( 1 = strongly disagree; 5 =strongly agree) to measure the LMX was used. The Cronbach's alpha for this scale was .91. A sample statement intended to secure LMX information read as follows: "My supervisor understands my job's problems and needs.". The individual work performance: Questionnaire (IWPQ) which consists of four dimensions: task performance, contextual performance, adaptive performance, and CWB (Koopmans et al., 2012) [49], was used to assess individual job performance. The questionnaire consists of 47 items, only part of it will be used for my research. Rating scale of the IWPQ is from 0-4. The questionnaire included items such as: How do you rate the quality of your own work in the past three months? "Insufficient"-"very good";
Compared to last year, I judge the quality of my work in the past three months to be "Much worse""much better"; How often was the quality of your work below what it should have been in the past three months? "Never"-“often".

\subsection{Hypotheses Testing}

All analyses were conducted on SPSS version 23 and PROCESS plugin version 2.16.3 for linear modelling and mediation effects analysis (Hayes, 2013) [50].

\subsubsection{Results}

Means, standard deviations, and zero-order correlations for the study variables for all participants are shown in "Table 1". Perceived cultural similarity was positively correlated with LMX quality, members' work performance. While the correlation between and all other variables were not significant except that actual cultural similarity was moderately associated with perceived similarity

Table 1. Means, standard deviations and correlations of variables $(\mathrm{N}=420)$

\begin{tabular}{|c|c|c|c|c|c|}
\hline Factor & $\mathrm{M}$ & SD & 1 & 2 & 3 \\
\hline 1. LMX & 3.78 & 0.63 & & & \\
\hline 2. Perceived cultural similarity & 3.56 & 0.68 & $.41^{* *}$ & & \\
\hline 3. Actual cultural similarity & 0.63 & 0.49 & .19 & $.28^{*}$ & \\
\hline 4. Job performance & 3.69 & 0.83 & $.43^{*}$ & $.40^{* *}$ & .17 \\
\hline
\end{tabular}

\subsubsection{Hypotheses1 Testing}

To test the hypothesis 1 that perceived cultural similarity would be a better predictor of outcomes that actual cultural similarity, linear modeling was conducted. The author of this article modeled the effect of LMX quality, actual and perceived cultural similarity on each of the dependent measures. The results of these analyses are reported in Table 2 . The results supported the first hypothesis. Perceived cultural similarity was positively and significantly related to LMX, while actual cultural similarity was not significantly related to LMX quality. $\gamma 03=-0.04, \mathrm{t}=-0.11$ 
Table 2. Modeling results

\begin{tabular}{lccc}
\hline & \multicolumn{3}{c}{ LMX Quality } \\
\cline { 2 - 4 } & Est & SE & $\mathrm{t}$ \\
\hline Intercept, $\gamma 00$ & 0.15 & 1.82 & 1.7 \\
Perceived cultural similarity $\gamma 01$ & 0.28 & 0.11 & $3.27 * *$ \\
Actual cultural similarity (ACD) $\gamma 02$ & -0.04 & 0.27 & -0.11 \\
\hline
\end{tabular}

$\mathrm{n}=420 ; * \mathrm{p}<.05, * * \mathrm{p}<.01, * * * \mathrm{p}<.001$

\subsubsection{Hypotheses2 Testing}

Following recommendations of Preacher and Hayes (2004) [51], the hypotheses2 test analysis utilizing the Bootstrap method ( sample size $=5000$ ) was conducted. No significant deviations concerning linearity, homogeneity, and homoscedasticity were observed.



Figure 2 The result of testing model of the relationship between PSC, ACS and JB through the meditational role of the LMX quality.

Note: path estimates represent unstandardized coefficients. Standard errors presented in parentheses. Direct effects after controlling for the mediator are shown in brackets. (PCS=Perceived cultural similarity, ACS $=$ Actual cultural similarity, LMX=leader-member exchange, JB=job performance) ${ }^{*} \mathrm{p}<0,10 * * \mathrm{*}, 0.05 * * * \mathrm{p}<0.01$.

\subsubsection{Mediation Effect Analysis}

A mediation effect model was tested in which LMX was a mediator, IV1: perceived cultural similarity and IV2: actual cultural similarity was predictors respectively, and JP: job performance was the consequence ("Figure 2"). The total effect of IV1: perceived cultural similarity on job performance was significant, $\mathrm{b}=0.33, \mathrm{t}=7.63$, $\mathrm{p}<$ .001. The direct effect of IV1: perceived cultural similarity on job performance was also significant $(\mathrm{b}=0.09, \mathrm{t}=2.87, \mathrm{p}<.01)$. IV1: perceived cultural similarity significantly predicted LMX $(b=0.56, t$
$=9.88, \mathrm{p}<.001)$. While the total effect of IV2: actual cultural similarity on job performance was not significant, $\mathrm{b}=0.14, \mathrm{t}=8.90, \mathrm{p}<.001$. The direct effect of IV2: actual cultural similarity on job performance was also not significant $(b=0.06, t=$ 2.77, $\mathrm{p}>.10)$. IV2: actual cultural similarity significantly did not predict LMX $(b=0.17, t=$ 9.88, $\mathrm{p}>.10)$.

A mediation model allows the isolation of the direct effects of perceived cultural similarity and actual cultural similarity. A bootstrapped analysis based on 5000 resamples revealed indirect effects of evaluation of LMX in both cases. Regression 
coefficient estimates and hypothesized indirect effects of (1) perceived cultural similarity $\rightarrow$ LMX quality $\rightarrow$ job performance (indirect effect $=0.47$, $\mathrm{SE}=0.06,95 \% \mathrm{CI}=[0.26,0.73])$ were significant; (2) actual cultural similarity $\rightarrow$ LMX quality $\rightarrow$ job performance (indirect effect $=0.09, \mathrm{SE}=0.03,95 \%$ CI $[0.02,0.07])$ was not statistically significant.

Pairwise comparisons between the indirect effects on the IV1 -DV and IV2-DV association were conducted to compare the strengths of these associations. Overall findings suggested that the direct effect of perceived cultural similarity on job performance through LMX quality was significantly, indicating a full mediation effect of LMX on the relationship between perceived cultural similarity. While the direct effect of actual cultural similarity through LMX quality was not statistically significant.

\subsection{Discussion}

Result of Linear modelling showed that a weak relationship between actual cultural similarity and LMX meant that actual cultural similarity in question was not a central predictor of LMX, and "that LMX would not play an important mediating role in the relationships involving such antecedent. On the contrary, perceived cultural similarity was positively and significantly related to LMX

Path analysis allowed for the estimation of true score correlations of the relationships among the antecedents, LMX, and consequences. Perceived cultural was proven to be the antecedent of LMX. That meant that perceived cultural similarity was a central predictor of LMX, and that LMX would play an important mediating role in the relationships involving such antecedent and significant indirect effect would be likely to exist. The author of this article mentioned before that not all the antecedents could be the variables that the LMX could mediate them to consequence as shown in the Dulebohn et al., (2012)'s [25] test. So, the author verified that perceived cultural similarity could be used as the antecedent that LMX could act as a mediator between it and outcomes. While the direct effect of actual cultural similarity through LMX quality was not statistically significant.

\section{CONCLUSION}

The author of this paper elaborates on an important distinction in cultural similarity that is reflected in the way it is conceptualized and measured. This study puts emphasis on comparing the influence of actual cultural similarity with perceived cultural similarity on LMX. As for the relationship between the ACS and PCS, there were some different views: some held that the relationships between actual and perceived dissimilarity were either very weak or did not exist at all. Others argued that actual group diversity was reliably related to perceptions thereof (Harrison et al. 2002[29]; Cunningham, 2007[19]). The author of this paper thinks that organizational culture, the degree of cultural diversity in the group, the desire to be better in job performance and the interact behavior between the leader and member are important effect factors owing to the consensus among the researchers that there is some cognitive element between the actual similarity and the perceived similarity.

The present study employs a cross-sectional design and future studies could use longitudinal designs. Future studies could also investigate both cultural diversity and LMX at multi-levels of analysis instead of only conducting at dyad level of analysis.

\section{AUTHORS' CONTRIBUTIONS}

This paper is independently completed by Chang Liu.

\section{REFERENCES}

[1] Bauer, T. N. Green, S. G. (1996). The Development of Leader-Member Exchange: A Longitudinal Test (J). Academy of Management Journal, 39, pp. 1538-1567

[2] Liden, R. C., \& Maslyn, J. M. (1998). Multidimensionality of leader-member exchange: An empirical assessment through scale development. Journal of Management, 24, 43-72.

[3] Henderson, D. J., Liden, R. C., Glibkowski, B. G., \& Chaudhry, A. 2009. Within-group LMX differentiation: A multilevel review and examination of its construct definition, 
antecedents and outcomes. The Leadership Quarterly, 4: 517-534.

[4] Martin, R., Thomas, G., Legood., A. Russo, S. D. (2017) Leader-member exchange (LMX) differentiation and work outcomes: Conceptual clarification and critical review. Journal of Organizational Behavior1-18

[5] Aycan, Z., \& Kanungo, R. N. (2001). Crosscultural industrial and organizational psychology: A critical appraisal of the field and future directions. In N. Anderson, D. Ones, H. K. Sinangil, \& C. Viswesvaran (Eds.), Handbook of industrial, work, and organizational psychology: Volume 1. Personnel psychology. Thousand Oaks, CA: Sage.

[6] Boyd, Brian K, Dess, Gregory G (1993), Divergence between archival and perceptual measures of the environment: causes and consequences. Academy of Management Review, Vol. 18, No. 2, 204-226.

[7] Dulebohn, Bommer, WH., Liden, RC., Brouer, RL, Ferris, GR. (2012). A MetaAnalysis of Antecedents and Consequences of Leader-Member Exchange: Integrating the Past with an Eye Toward the Future. Journal of Management Vol. 38 No. 6, November 1715-1759

[8] Rockstuhl, T, Dulebohn, J. H, \& shore, L M.. (2012). Leader - member exchange (LMX) and culture: a meta-analysis of correlates of LMX across 23 countries. Journal of applied psychology,6:97-130

[9] Anderson, Carl R., P, Frank T. (1975). Managerial Perceptions and Strategic Behavior. The Academy of Management Journal 18(4):811-823

[10] Beugelsdijk. S., Ambos, B., Phillip, C Nell. (2018). Conceptualizing and measuring distance in international business research: Recurring questions and best practice guidelines Journal of International Business Studies 49, 1113-1137

[11] Hofstede, G. (1980). Culture's consequences: International differences in work-related values. New Bury Park, CA: Sage;
[12] Shenkar, O. (2001). Cultural distance revisited: Towards a more rigorous conceptualization and measurement of cultural differences. Journal of International Business Studies, 32(3):519-535.

[13] Lott, B. (2010). Multiculturalism and Diversity. Oxford: A John Wiley \& Sons, Ltd., Publication.

[14] Tajfel, H., \& Turner, J. (1986). An Integrative Theory of Intergroup Conflict. In W. G. Austin, \& S. Worchel (Eds.), Psychology of Intergroup Relations (pp. 7-24). Monterey, CA: Brooks Cole.

[15] Turner, J. C. (1987). Toward a cognitive redefinition of the social group. In Henri Tajfel (ed.), Social identity and intergroup relations ( $\mathrm{p}$ 15-40). Cambridge: Cambridge University Press.

[16] Layton, B. D., \& Insko, C. A. (1974). Anticipated interaction and the similarityattraction effect. Sociometry, 37, 149-162.

[17] Matkin, et al., (2012). Demographic Similarity/Difference, Intercultural Sensitivity, and Leader-Member Exchange: A Multilevel Analysis. Journal of Leadership \& Organizational Studies 19(3) $294-302$

[18] Montoya, R. M., Horton, R. S., \& Kirchner, J. (2008). Is actual similarity necessary for attraction? A meta-analysis of actual and perceived Similarity. Journal of Social and Personal Relationships, 25, 889-922.

[19] Cunningham, G. B. (2007). Perceptions as reality: The influence of actual and perceived demographic dissimilarity. Journal of Business and Psychology, 22, 79-89.

[20] Shemla, et al., (2016) A review of perceived diversity in teams: Does how members perceive their team's composition affect team processes and outcomes? Journal of Organizational Behavior, J. Organiz. Behav. 37, S89-S106

[21] Hui, C., Law, K. S., \& Chen, Z. X. (1999). A structural equation model of the effects of negative affectivity, leader-member exchange, and perceived job mobility on in-role and extra-role performance: A Chinese case. 
Organizational Behavior and Human Decision Processes, 77: 3-21.

[22] Gerstner, C. R., \& Day, D. V. (1997). Metaanalytic review of leader-member exchange theory: Correlates and construct issues. Journal of Applied Psychology, 82: 827-844

[23] Bass, B. M., \& Avolio, B. J. (1993). Transformational leadership: A response to critiques. In M. M. Chemers \& R. Ayman (Eds.), Leadership theory and research: Perspectives and directions: 49-88. San Diego, CA:Academic Press.

[24] Jiang, Z., Le, H., and Gollan, P. J. (2018). Cultural intelligence and voice behavior among migrant workers: the mediating role of leader-member exchange The International Journal of Human Resource Management

[25] Dulebohn, JH., Bommer, WH., Liden, RC., Brouer, RL, Ferris, GR. (2012). A MetaAnalysis of Antecedents and Consequences of Leader-Member Exchange: Integrating the Past with an Eye Toward the Future. Journal of Management Vol. 38 No. 6, November $1715-1759$

[26] Byrne, D. (1971). The Attraction Paradigm. New York Academic Press. Carpenter, M. A. 2002. The implications of strategy and social context for the relationship between top management team heterogeneity and firm performance. Strategic Management Journal, 23: $275-284$.

[27] Condon, J. W., \& Crano,W. D. (1988). Inferred evaluation and the relation between attitude similarity and interpersonal attraction. Journal of Personality and Social Psychology, 54,789-797.

[28] Ptacek, J., \& Dodge, K. (1995). Coping strategies and relationship satisfaction in couples. Personality and Social Psychology Bulletin, 21, 76-84.

[29] Harrison, D. A., Price, K. H., Gavin, J. H., \& Florey, A. T. (2002). Time, teams, and task performance: Changing effects of surface- and deep-level diversity on group functioning. Academy of Management Journal, 45, 10291045
[30] Hooghe, M., \& de Vroome, T. (2013). The perception of ethnic diversity and antiimmigrant sentiments: A multilevel analysis of local communities in Belgium. Ethnic and Racial Studies, 38, 38-56

[31] Downey, H. K., Hellriegel, D., \& Slocum, J. W. (1975). Environmental uncertainty: The construct and its application. Administrative Science Quarterly, 20: 613-629.

[32] Cook, C. and Hunsaker, P.L (2001) Management and Organizational Behavior. 3rd Edition, Irwin McGraw-Hill, New York.

[33] Coleman, Peter T. (2000). The handbook of conflict resolution: theory and practice. Adr Bulletin

[34] Allport, G. W. (1979). The nature of prejudice. Reading, MA: Addison-Wesley.

[35] Pettigrew, T. F. (1998). Intergroup contact theory. Annual Review of Psychology, 49, $65-85$.

[36] Dekker, Wim den Global Mindset and CrossCultural Behavior (2016). Springer Nature The registered company is Macmillan Publishers Ltd. London

[37] Blau, P. M., 1964. Exchange and power in social life New York: Wiley

[38] Foa, E. B., \& Foa, V. G. (1980). Resource theory: Interpersonal behavior exchange. In K.J. Gergen, M. S. Greenberg, \& R. H. Willis (Eds.), Social exchange: Advances in theory and research. New York: Plenum.

[39] Erdogan, B., \& Bauer, T. N. (2010). Differentiated leader-member exchanges: The buffering role of justice climate. Journal of Applied Psychology, 95: 1104-1120.

[40] Brower, H. H., Schoorman, F. D., \& Tan, H. H. (2000). A model of relational leadership: The integration of trust and leader-member exchange. Leadership Quarterly, 11: 227-250.

[41] Maslyn, J. M., \& Uhl-Bien, M. (2001). Leader-member exchange and its dimensions: Effects of self-effort and other's effort on relationship quality. Journal of Applied Psychology, 86: 697-708. 
[42] Cogliser, C. C., Schriesheim, C. A., Scandura, T. A., \& Gardner, W. L. (2009). Balance in leader and follower perceptions of leadermember exchange: Relationships with performance and work attitudes. Leadership Quarterly, 20: 452-465.

[43] Javidan, M., Peter, W. Dorfman, Mary, Sully de Luque and Robert J. House. In the Eye of the Beholder: Cross Cultural Lessons in Leadership from Project GLOBE Academy of Management Perspectives, Vol. 20, No. 1 (Feb., 2006), pp. 67-90

[44] Mitchell, J., Neubert, Dawn, S., Carlson, K., Michele, Kacmar, James. (2009). The Virtuous Influence of Ethical Leadership Behavior: Evidence from the Field Journal of Business Ethics

[45] Turban, DB., Jones, AP. (1988). Supervisorsubordinate similarity: types, effects, and mechanisms. Journal of Applied Psychology

[46] Liden, R. C., Wayne, S. J., \& Stilwell, D. (1993.) A longitudinal study on the early development of leader-member exchanges. Journal of Applied Psychology, 78: 662-674.

[47] Ghemawat, Pankaj (2011) Stretching Your Global Mindset. Harvard Business Review Blog Network

[48] Graen, G. B., \& Uhl-Bien, M. ( 1995 ) . Relationship-based approach to leadership: Development of leader - member exchange (LMX) theory ofleadership over 25 years: Applying a multi-level multi-domain perspective. Leadership Quarterly, 6, 219 247.

[49] Koopmans, L., Bernaards, C. (2012). Development of an individual work performance questionnaire. International Journal of Productivity and Performance Management

[50] Hayes, A. F. (2013). Introduction to mediation, moderation, and conditional process analysis: A regression-based approach. New York, NY: Guilford Press.

[51] Preacher, K. J., \& Hayes, A. F. (2004). SPSS and SAS procedures for estimating indirect effects in simple mediation models. Behavior Research Methods, Instruments, \& Computers, 36(4), 717-731. 